\title{
Lingkungan Fisik Situs Wonoboyo Ditinjau Dari Aspek Geografi
}

\author{
nfn. Sunarto \\ Soenarso Simoen \\ nfn. Jamulya
}

Keywords: environment, stratigraphy, geography, Hindu-Buddha, archaeology

\section{How to Cite:}

Sunarto, nfn., Simoen, S., \& Jamulya, nfn. Lingkungan Fisik Situs Wonoboyo Ditinjau Dari Aspek Geografi. Berkala Arkeologi, 13(3), 59-72. https://doi.org/10.30883/jba.v13i3.617

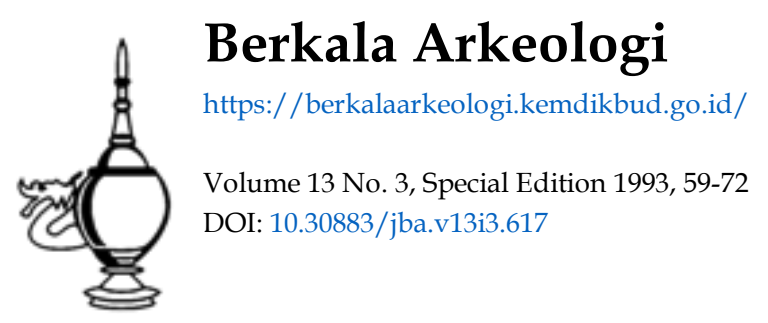

\section{(c) (1) (2)(2)}

This work is licensed under a Creative Commons Attribution-NonCommercial-ShareAlike 4.0 International License. 


\title{
LINGKUNGAN FISIK SITUS WONOBOYO DITINJAU DARI ASPEK GEOGRAFI
}

\author{
Olen: \\ Sunarto \\ Soenarso Simoen \\ Jamulya
}

\section{ABSTRAK}

Sitw Wonaboyo terletak di datanas aluvial kaki gunungapi Menapi. Berdasarkan pengamatan pedostratignafi, situs ini tertimbun endapan lahar setebal rata-rata $2 \mathrm{~m}$, dan di bawah endapan lahar ini telah derbentuk tanah pada taraf yuvenil. Data geolistrik dan pemboran menunjukkan, bahwa kawasan situs ini meluas ke arah utaira hingga hawaran di utara jalan lingkar utara Desa Plosokuning. Pendekatan sistem perlu diterapkan untuk mengusahakan pengeloloan sumberdaya arkeologi. Berdasarkan masukan data geografi, diperoleh keluaran, bahwa situs ini perlu dimasukkan ke dalam kawasan cagar budaya, sebab: (a) kawasan temuan ada di sempadan sungai yang harus dilindungi, (b) kawasan ini trmasuk subur, sehingga perkembangan permukiman lebih cepat daripado penelitian arkeologi, (a) kawasan ini merupakan daerch rentan bahaya alinan lahar dan gempe bumi.

\section{PENDAhuluan}

Makalah seminar Inl bermaksud menelaah kondisl lingkungan sisik Sltus Wonoboyo dari sudut pandang geografi. Hasil tolaah InI diharapkan dapat bermantaat sobagal masukan dalam salah satu dasar penyusunan rencana pengelolaan sumberdaya arkeologl Sltus Wonoboyo.

Slstematika ponyusunan makalah inl terdirl atas geomortologl, pedostratlgrafi, hidrologl, pendugaan geollstrlk, dan pongololaan sumberdaya arkeologls dengan pendekatan slstem. Berlkut InI akan disajkkan ulasan darl kollma hal torsobut.

\section{GeOMORFOLOQI}


Situs Wonoboyo terletak pada ketingglan sekitar $164 \mathrm{~m}$ dpal., yang socara geomorfologls, terletak pada satuan fislografl dataran aluvial kakl Gunungapl Merapl. Topografl daerah Inl termasuk datar dengan sudut lereng umum berklsar $0^{\circ}-2^{\circ}$ dengan lereng berarah ke selatan-Tenggara. Material batuannya terjadl darl hasll letusan Gunungapl Merapl yang berupa endapan lahar, tuff, dan breksi vulkanlk.

Ditinjau darl asal material batuannya, daerah Wonoboyo ini terpasok dari Gunungapl Merapt. Gunungapl Merapl merupakan salah safu Gunungapl aktif di Jawa. Gunungapl ini tumbuh dan berkembang pada suatu persilangan antara sesar mellintang dan sesar membujur yang membelah Pulau Jawa Inl (Verstappen,1988). Bemmelen (1970) mengemukakan, bahwa sesar melintang berarah Utara-Selatan, yang momisahkan Jawa Timur darl Jawa Tengah. Lintang membujur Derarah ke Timur-Barat yang membentuk bates antara Perbukltan Kendeng bagian barat dan Subzone Ngawl. Kedua Jents sesar yang saling bersilangan tersebut digambarkan dengan jelas oleh Kloosterman (1989) seperti tercantum pada Gambar 1.

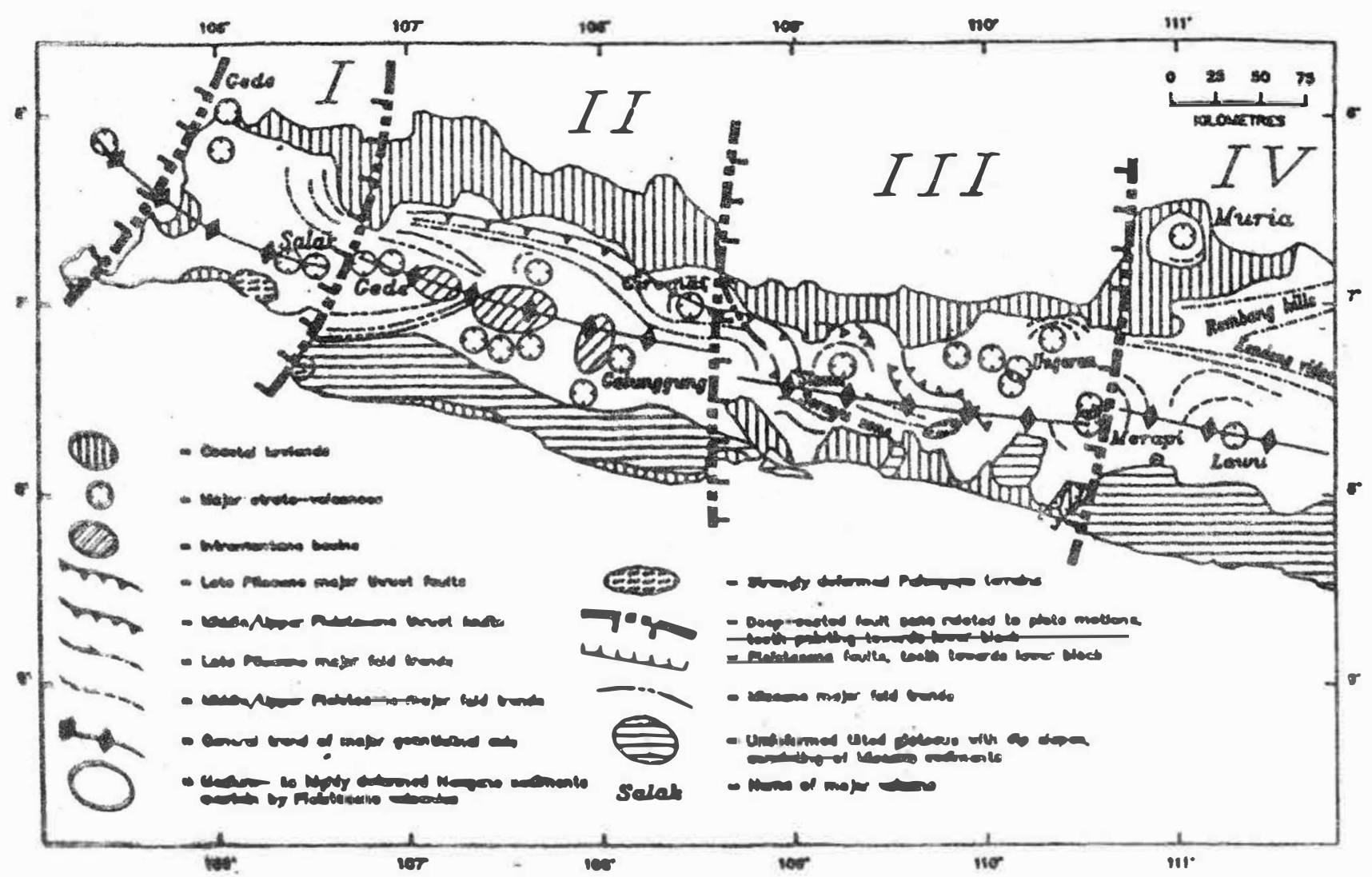

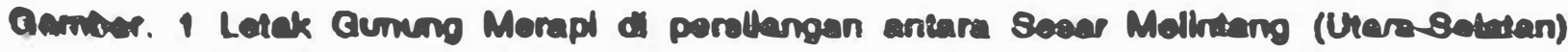
dan Secer Membutur (Tlmur-Baral) (Bumber: Kboeterman, 1909) 
Bemmelen (1970) mengemukakan, bahwa Gunungapi Merapl pada tahun 1006 meletus dengan hebat sehingga memusnahkan penduduk dan memporak-porandakan Kerajaan Hindu yang makmur di Jawa Tengah. Letusan tersebut juga mengakibatkan lahan subur di sekltar gunungapl Inl menjadl gurun yang tertutup oleh abu vulkanlk gersang. Erupsi katastroflk Gunungapl Merap' pada tahun 1006 tersebut aklbat gabungan darl tlga macam tenaga alam, yaltu: tenaga tektonlk, tenaga gravitasi, dan tenaga vulkanik.

Tenaga tektonlk lit menimbulkan gerak pemicu, sehingga merusakkan kerucut gunungapl Merapl Tua. Tenaga gravltasl menyebabkan peruntuhan dan penggellnclran sebaglan besaf kerucut gunungapl Merapl Tua ke arah barat ke Lembah Progo. Tenaga vulkanik menyebabkan ledakan hebat yang katastrofik. Gabungan ketlga tenaga tersebut menyebabkan kerucut gunungapl Merapl Tua mengalaml sesar-gelinclr hlperbollk yang cekung ke arah barat (Gambar 2).

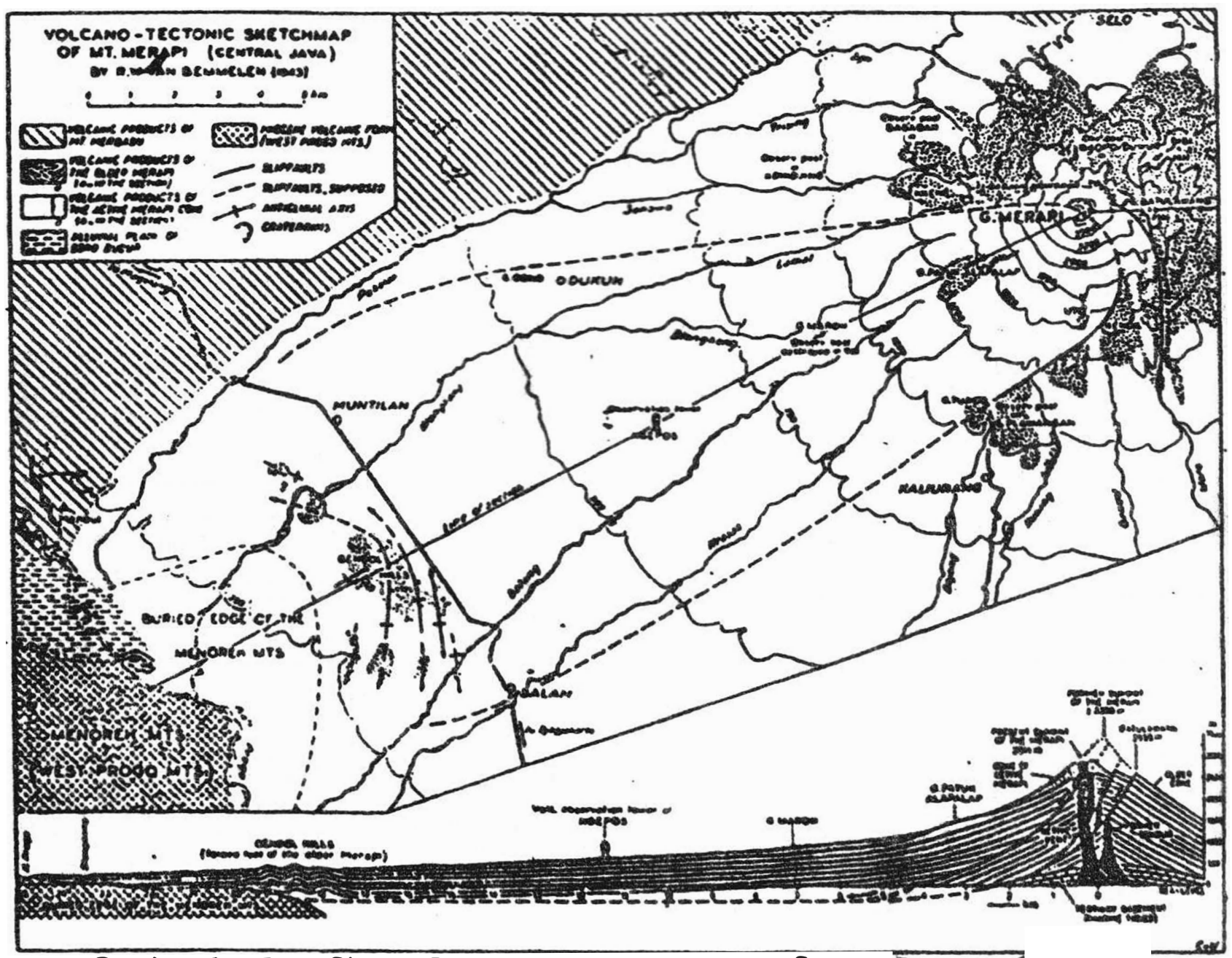

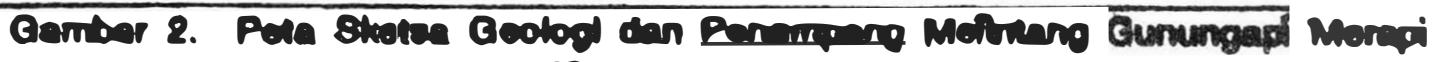

(Bommiten, 1970) 


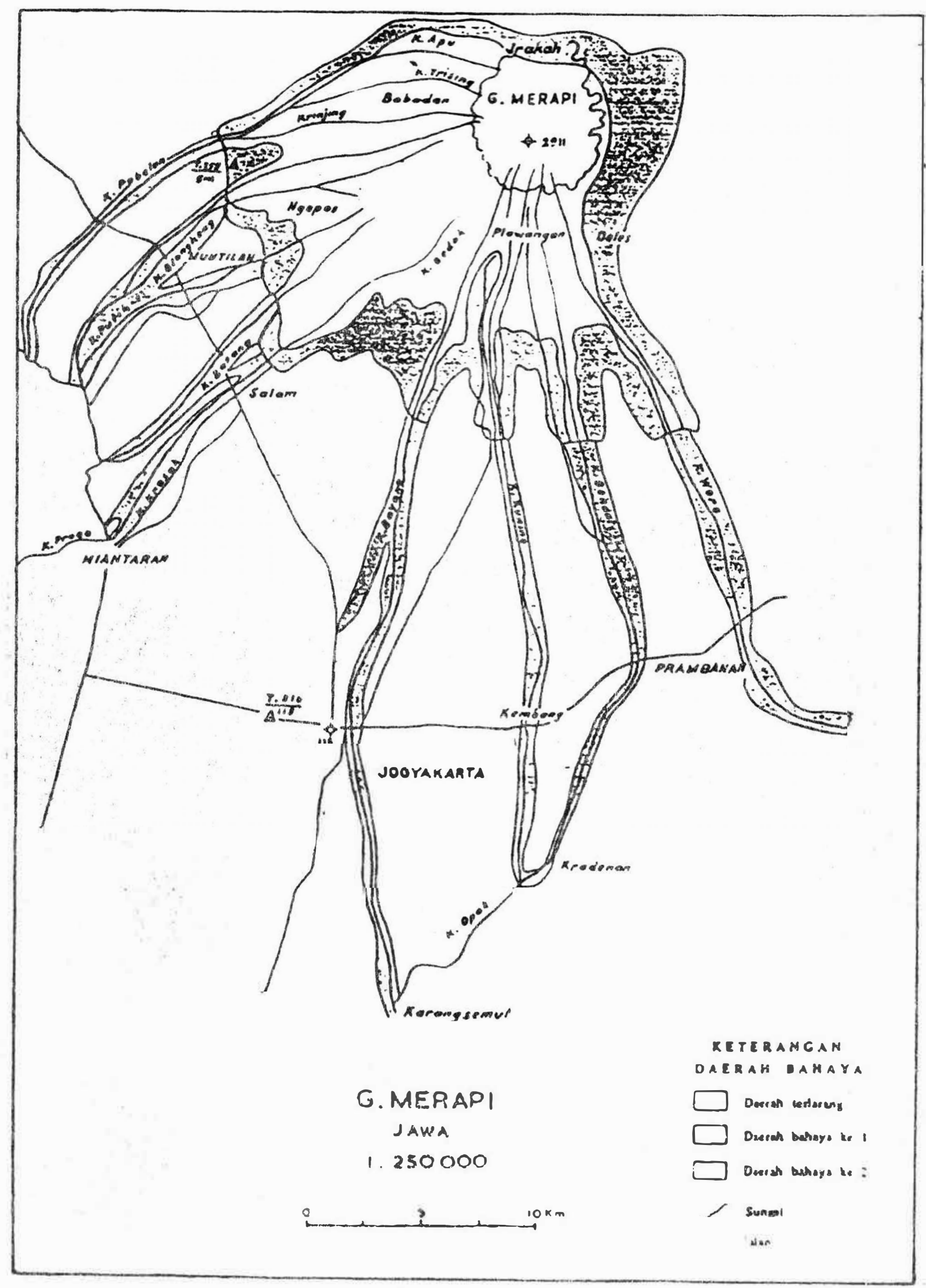

Gember 9. Pota Bahaya Gunungapi Morapi (Roksoutrogo, 1978) 
Menurut Reksowirogo (1979), Kall Woro merupakan salah satu sungai yang termasuk kedalam daerah bahaya II (lihat Gambar 3). Daerah bahaya II lalah daerah yang dapat terancam oleh bahaya sekunder yang berupa aliran lahar hujan. Karena Situs Wonoboyo terletak tidak jauh darl Kali Woro atau Kali Wedi, maka merupakan hal alami jika situs tersebut tertimbun oleh endapan material vulkanik.

Pada citra Landsat tampak jelas (Gambar 4), bahwa Kali Woro merupakan sungai sesar, sebab sungai ini mengikuti garis sesar yang terjadi di sayap Selatan-Tenggara Gunungapi Merapi. Di sepanjang garis sesar, pada umumnya merupakan daerah bahaya potensial terhadap gempa. Telah diketahul bersama, bahwa gempa bumi merupakan bahaya alam yang berpotensi untuk meruntuhkan berbagai bangunan.

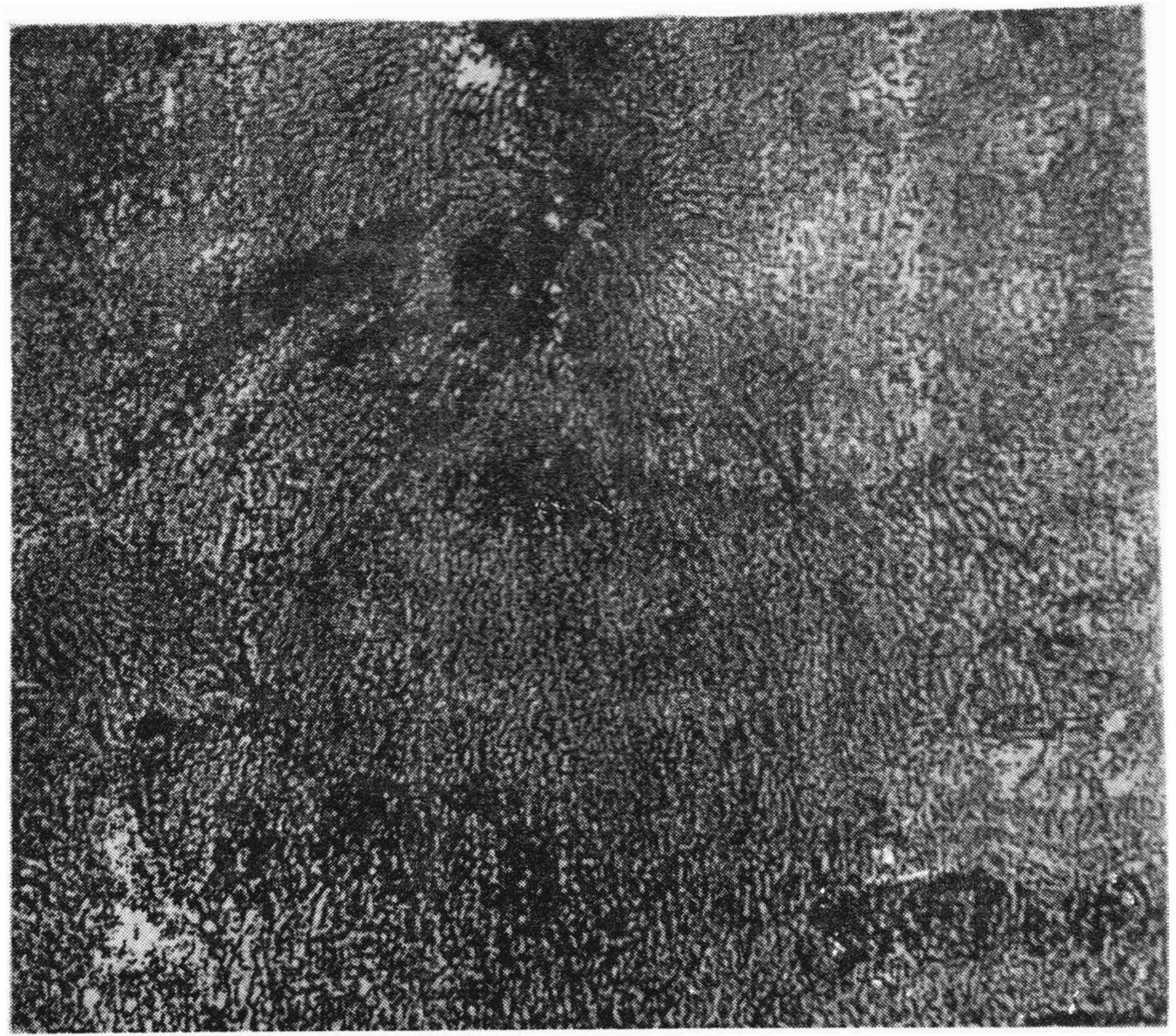

Gambar 4. Chra Landaal Gunungapl Morapi dan Sokitarnya 


\section{PEdostratigrafi}

Tanah di Sltus Wonoboyo berasal dari bahan Induk endapan lahan dan ondapan fluvial hasll rombakan bahan plroklastlk letusan Gunungapi Merapi. Ukuran butir bahan endapan tersebut berupa boulder, gravel, pasir, dan debu.

Perkembangan tanah di Sltus Wonoboyo Inl maslh dalam taraf awal flnftlal stageh yang termasuk jenis tanah Regosol (Tropopsamments). Tanah ini belum mengalami diferenslasi horlzon, sehlngga profll tanahnya homogen. Slfat tanah yang dlamatl antara lain: tekstur pasir berdebu hingga pasir debu berkerlkil, struktur berbutir tunggal hingga remah, konsistensi lepas-lepas, permeabllitas cepat, warna tanah kelabu hingga coklat kekelabuan (10YR4/1-3). Di dalam tanah inl sering dljumpal bentukan padas, yang merupakan hasll sementasl partikel-partlkel pasir oleh abu vulkanik atau tuff Si dan Fe pada kedalaman $30 \mathrm{~cm}$ hingga $150 \mathrm{~cm}$. Tanah di kawasan sltus inl mengandung bahan organlk yang rendah dengan pH 5,5 - 6,5.

Kesuburan tanah, secara mineralogis kaya akan mineral primer yang belum lapuk, tetapl darl slfat fisiknya, bertekstur kasar, permeabllitas cepat, daya serap kation rendah, daya adesif alr rendah, sehingga memerlukan alr irigasi yang banyak. Karena tingkat pelapukan bahan Induk maslh pada tarat awal, maka ketersediaan unsur hara masih rendah, sehlngga kesuburan kimlanya rendah. Unsur $N$ kurang, sedangkan unsur $P$ dan $K$ cukup tersedla, dalam hal Inl $P_{2} \boldsymbol{O}_{5}$ berkisar 0,14-0,22\% dan $K_{2} \mathrm{O}$ berkisar 0,08-0,05\%.

Sebagal gambaran slfat morfologl profll tanah dl Sltus Wonoboyo. berlkut Inl disajlkan hasil pemerlan profll pewakll.

Nomor Profil

Lokesl

Fisiografi

Rellef

Lthologl

Penggunaan lahan

Klaslfikasl tanah
: Profll pewakll.

: Plosokuning (Wonoboyo).

: Dataran aluvlal kakl gunung apl Merapl.

: Datar (lereng < 6\%).

$\because$ : Endapan rulkanlk

: Sawah Irlgasl musiman/tahan kering

: Rogosol (Tropopsammonts) 


\begin{tabular}{|c|c|c|}
\hline $\begin{array}{l}\text { Lapisan } \\
\text { tanah }\end{array}$ & $\begin{array}{l}\text { Kedalama } \\
(\mathrm{cm})\end{array}$ & Pemerlan \\
\hline$A p$ & $0-25$ & $\begin{array}{l}\text { Paslr kasar berdebu, berbutlr tunggal hingga } \\
\text { remah, lepas-lepas hingga gembur, coklat } \\
\text { kekelabuan gelap (10YR4/2), permeabllitas } \\
\text { cepat, poreous, kandungan kerikll 5\%, kandungan } \\
\text { bahan organlk rendah, pH } 6,0 \text { hingga } 6,5 \text {, batas } \\
\text { lapisan lurus. }\end{array}$ \\
\hline
\end{tabular}

Cn 25 - 55 Lapisan padas olah, pasir berdebu, pejal mema dat akibat daya beban berat waktu pengolahan dan juga adanya sementasi oleh $\mathrm{Fe}$ dan Si, coklat tua (10YR4/3), permeabllitas sedang, pH 6,0 - 6,5, batas laplsan lurus.

C1 55 - 90 Pasir kasar, berbutir tunggal, lepas-lepas, co klat kekelabuan (10YR 4/3), permeabilltas cepat, kandung-kerikil > 5\%.

C2 $>90 \quad$ Pasir kasar berdebu, kandungan kerikll >10\% berbutir tunggal,lepas-lepas, permeablitas sangat cepat, sangat poreous.

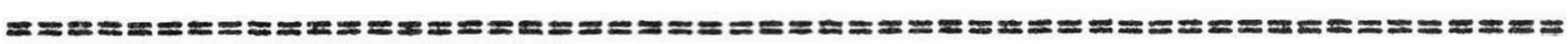

Bendasarkan pengamatan enam profil pewakll pada beberapa lubang ekskavasl, maka dapat dlulas kondisl pedostratigrafi dl Sltus Wonoboyo sepertl berlkut ini.

1. Lapisan budaya masa lampau (paleocultural layer) ada pada bentang tanah masa lampau (paleosollscape). Bentang tanah masa lampau Inl terkubur oleh endapa lahar dan ondapan fluvlal rata-rata setebal $200 \mathrm{~cm}$.

2. Laplsan budaya masa lampau diclrlkan oleh tanah yang telah berkembang pada taraf muda (yuvenil), coklat kelam (10YA4/3), pasir bergeluh, remah-gumpal, lekat (basah) atau gembur (lembab), bahan organlk relatlf tinggl, dan pH 5,5 6.5. Sebagal buktl adanya akthltas pada masa lampau yaknl: 
fragmen batubata, batu putlh (aglomerat) dari Perbukltan Baturagung (Gunungkdul) di solatan Situs Wonoboyo, po cahan gerabah, fosil daun, kayu, dan arang.

3. Materlal yang mengubur tanah masa lampau berupa tuff dan abu vulkanlk, endapan cuclan permukaan (surface wash deposits). serta endapan lahar dan endapan flu vlal. Kedua endapan terakhir liu menjadl bahan Induk bagi tanah-tanah yang terbentuk sekarang.

\section{HIDROLOGI}

Sebelum mengulas tentang kondisi geohidrologi Situs Wonoboyo. terleblh dahulu dlulas tentang kondisi $\mathrm{Ikllm}$ di daerah tersebut berdasarkan data Iklim dari Stasiun Klimatologi Lanuma Adisuclpto. Yogyakarta. Suhu rata-rata tahunan di daerah Inl sekltar $25,75^{\circ} \mathrm{C}$. Kelembaban udaranya dipengaruhi oleh musim kemarau dan musim penghujan. Kelembaban nisbl di musim kemarau rata-rata sebesar $<60 \%$, sedangkan pada musim penghujan dapat mencapal $>95 \%$. Rata-rata kelembaban nisbl tahunan adalah $82 \%$.

Kecepatan angin rata-rata sekitar $10 \mathrm{~m} / \mathrm{jam}$ dengan arah dominan dari Tenggara ke Baratlaut pada musim kemarau, sedangkan pada musim penghujan arah angln dominan darl Baratlaut ke Tenggara. Rata-rata curah hujan tahunan sebesar $2090 \mathrm{~mm}$. Curah hujan bulanan tertinggl Jatuh pada bulan Januarl, yaltu $380 \mathrm{~mm}$, sedangkan curah hujan bulanan terendah Jatuh pada bulan Agustus yakni sebesar $20 \mathrm{~mm}$. Berdasarkan data tersebut dapatlah diketahul, bahwa Ikllm di Situs Wonoboyo adalah A m pada klasifikasi tlpe Ikllm Koppen.

Ditinjau darl hidrogeologi, situs inl termasuk pada satuan akulfer produktif dengan keterusan sedang hingga tinggl, muka air tanah dangkal, deblt sumur berkisar 5-10 llter/detlk (Djaenl, 1982). Kondlsl alr tanah ini memungkinkan bermukimnya penduduk dl daerah Inl, karena penduduk mudah untuk mendapatkan air bagl keperluan hidupnya.

\section{PENDUGAAN GEOLISTRIK}

Pendugaan geollstrlk dllakukan dengan cara Schlumberger dan cara Wenner. Cara Schlumberger digunakan untuk mengetahul stratigrafl batuan ke arah dalam, sedangkan cara Wenner digunakan 
untuk "merajang" arah horizontal pada ketebalan lapisan tertentu, dalam penelltian Inl lapisan setebal $4,5 \mathrm{~m}$.

Salah satu hasll pendugaan geollstrik cara Schlumberger adalah sebagal berlkut.

\begin{tabular}{|c|c|c|}
\hline $\begin{array}{c}\text { Kedalaman } \\
(\mathrm{m})\end{array}$ & $\begin{array}{c}\text { Tahanan Jenis } \\
(\text { Ohm })\end{array}$ & \multicolumn{1}{|c|}{ Pemerlan } \\
\hline $0,0-0.9$ & $600-720$ & Pasir kering \\
$0.9-3,5$ & $210-360$ & Pasir vulkanlk halus \\
$3,5-6,0$ & $65-75$ & Tanah masa lalu \\
$6,0-60,0$ & $42-48$ & Pasir jenuh air tanah \\
\hline
\end{tabular}

(Anonim, 1992)

Hasil pendugaan geolistrik dengan cara Wenner dapat diringkas sebagal berikut Ini.

\begin{tabular}{|c|c|c|}
\hline Tahanan Jenls (Ohm) & Pemerian & Persebaran \\
\hline $\begin{array}{l}<10 \\
<100 \\
300-400 \\
600-800\end{array}$ & $\begin{array}{l}\text { Gambut } \\
\text { Material basah } \\
\text { Onggokan batu dan } \\
\text { pecahan bal bata. } \\
\text { Endapan lahar }\end{array}$ & $\begin{array}{l}\text { Barat Desa Ploso kuning. } \\
\text { - Di tepi sungal } \\
\text { Timur desa } \\
\text { Baglan selatan }\end{array}$ \\
\hline
\end{tabular}

\section{PENGELOLAAN SUMBERdAyA ARKEOLOGIS}

Sesual dengan Kerangka - Acuan Temu Evaluasi Penelltian Wonoboyo, maka di dalam Subbab ini akan diulas tentang pengelolaan sumberdaya arkeologis dengan pendekatan sistem. Pengelolaan pada umumnya mellputl tlga keglatan utama, yaltu perencanaan, pelaksanaan, dan pengembangan. Ketiga kegiatan tersebut akan diulas berdasarkan konsep sistem. Suatu sistem pada umumnya mempunyal tlga baglan, yaltu masukan, proses, dan keluaran. Untuk memudahkan dalam pemahaman pengelolaan sumberdaya arkeologls dengan pendekatan slstem. dlpersllakan menglkutl Gambar 5. 


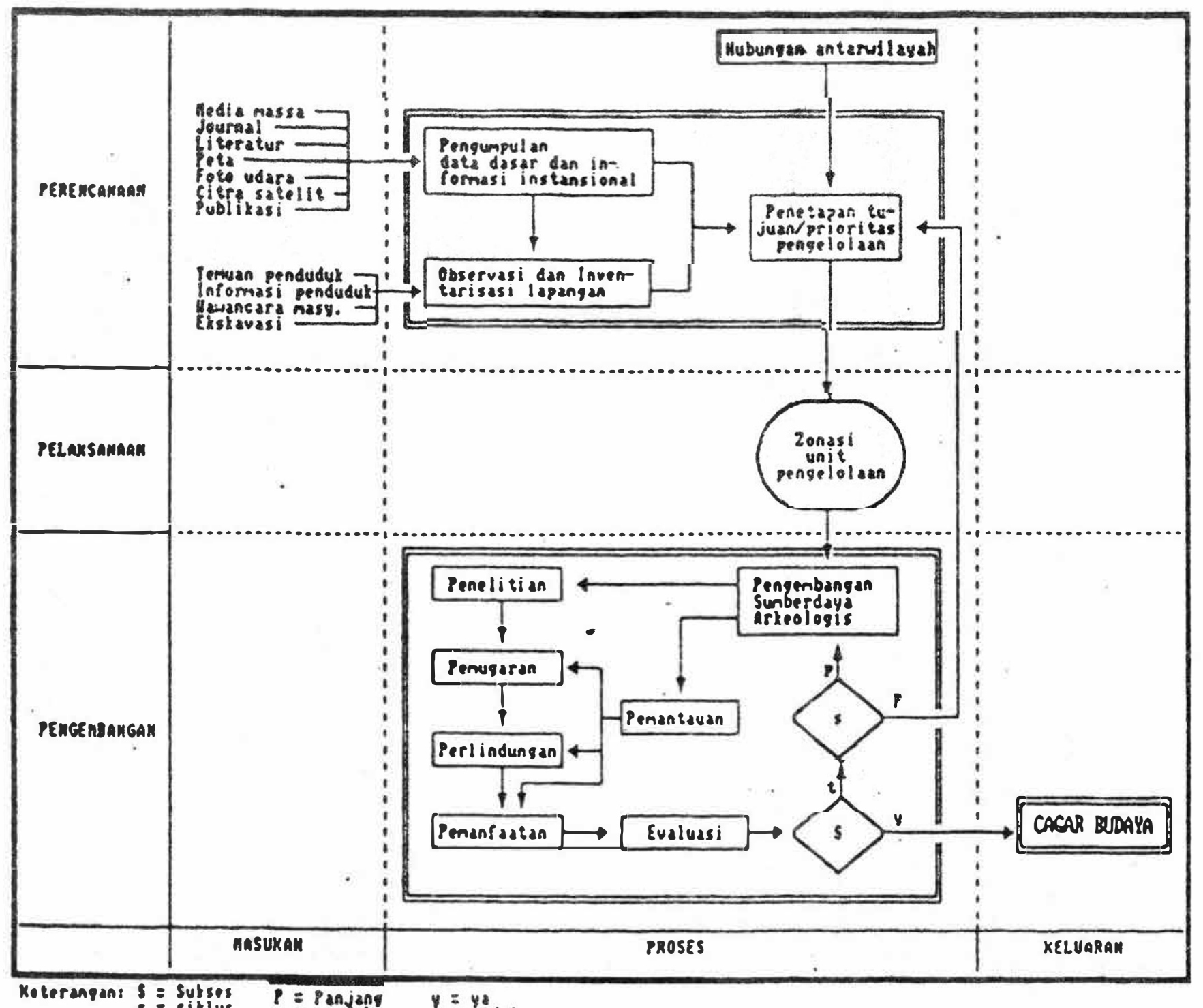

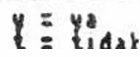

\section{Cambar 6. Diagram Nir Pengololenn Sumberdaya Arkoobogle denoan Pondokntan Sierem}

Dalam gambar tersebut dapat diketahul, bahwa sumbu $x$ menggambarkan baglan-baglan sistem (masukan, proses, dan keluaran). sedangkan sumbu y menggambarkan keglatan-keglatan utama dalam proses pengelolaan (perencanaan, pelaksanaan, dan pengembangan). Berikut inl dlulas masing-masing keglatan dl dalam sistem.

Proses pengelolaan sumberdaya arkeologls yang dlkemukakan di dalam makalah ini mellputi lima keglatan sebagal berlkut Ini. 
rata-rata $2 \mathrm{~m}$, dl bawah endapan lahar ini pernah terbentuk tanah (yuvenil). DI atas tanah itu telah ada aktlvitas penduduk dengan dijumpainya susunan potongan batuan aglomerat yang bukan batuan insitu, melainkan batuan exsitu yang berasal dari Pegunungan Baturagung di Gunungkidul.

5. Data geolistrik dan pemboran menunjukkan, bahwa kawasan Situs Wonoboyo meluas ke arah utara hingga kawasan dl utara jalan lingkar utara Desa Plosokuning.

6. Untuk mengusahakan pengelolaan sumberdaya arkeologis Situs Wonoboy perlu dilakukan dengan pendekatan sistem, sebab akan lebih jelas urut-urutan proses -pengelolaannya, data masukannya, dan hasil keluarannya. Berdasarkan data geografi sebagal masukannya, diperoleh keluaran bahwa Situs Wonoboyo perlu dimasukkan sebagai cagar budaya, sebab:

a. Kawasan temuan (perhlasan emas) terletak di kawasan lindung sempadan sungal (Keppres No.32/1990).

b. Kawasan Wonoboyo iermasuk kawasan yang relatif subur, sehingga perkembangan permukiman akan lebihcepat daripada. penelitian arkeologl.

c. Kawasan Wonoboya merupakan daerah yang rentan ter hadap bencana alam, balk berupa bencana aliran lahar maupun bencana gempa bumi. 


\section{KEPUSTAKAAN}

Anonim, 1992, Keglatan Ponentuan Batee Wilayah Cagar Budaya Dalam Rangka Ponyolamatan Sltus Wonoboyo, Laporan Penelltian, Jakarta: Kerjasama antara BAKOSURTANAL, DITLINBINJARAH, dan Fakultas Geografi UGM.

Bemmelen, R.W. van, 1970, The Geology of Indonesia, Vol. IA (General Geology of Indonesia and Adjacent Archipelagoes), Edisi ke-2, The Hague: Martinus Nijhoff.

Djaeni, A., 1982, Pota Hidrogeologi Indonesia 1:250.000, - Lémbar IX Yogyakarta (Jawa), Bandung: Direktorat Geologl Tata Lingkungan.

Kloosterman, F.H., 1989, Groundwater Flow Systems in the Northern Coastal Lowlands of West and Contral Java, Indonesia: An Earth-Scientific Approach, Disertasl, Amsterdam: Free University.

Reksowirogo, L.D., 1979, Merapl, dalam: K. Kusumadinata (Ed.h Data Dasar Gunungapl Indonesia, Bandung: Direktorat Vulkanologi.

Verstappen, H. Th., 1988, Excurtion Gulde, Pre-26 th International Geographlcal Congress, Symposium Working Group on Geomorphological Surveying and Mapping. Yogyakarta: Faculty of Geography, Gadjah Mada University. 